\title{
Evaluation of body image, sexual dysfunctions and quality of life in female patients with generalized anxiety disorder
}

\author{
ÖZGÜL KARAASLAN1, Yunus HacimuSAlar ${ }^{1}$ \\ ${ }_{1}$ Bozok University, Medical Faculty, Psychiatry Department, Yozgat, Turkey.
}

Received 6/7/2018 - Accepted: 10/10/2018

DOI: 10.1590/0101-60830000000178

\begin{abstract}
Objective: This study aimed to compare the patients with GAD in terms of SD, body perception and quality of life with healthy controls. Methods: The study included 41 female patients and 40 healthy female individuals with an aged between 18-50 years, regular sexual life and married. The Arizona Sexual Experiences Scale(ASEX), Short Form 36(SF-36), Body Cathexis Scale(BCS) and Beck Anxiety Inventory were used in the subjects. Patients with chronic illness, comorbid psychiatric, endocrine, alcohol or substance use disorder, drug use that could impair sexual function, pregnant, lactation, were not included in the study. Results: In ASEX, high scores were found in 44\% of GAD patients and 17.5\% of the control group in terms of SD. Sexual desire, arousal, lubrication, and orgasm scores of ASEX correlated with the body dissatisfaction in GAD patients. Physical function, general health status, mental health scores of SF-36 were found lower in the GAD group. Discussion: As a result of these findings, it can be suggested that sexual function, body image and quality of life are negatively affected in GAD patients and that deterioration of them should be questioned as well as symptomatic relief in patients' follow-up and treatment.
\end{abstract}

Karaaslan Ö et al. / Arch Clin Psychiatry. 2018;45(6):150-3

Keywords: Generalized anxiety disorder, sexual dysfunction, body image, quality of life.

\section{Introduction}

Generalized anxiety disorder (GAD) is a disorder characterized by symptoms such as excessive anxiety and worry about the events and activities, difficulty in controlling the worry, restlessness, easy fatigue, muscle tension and sleep disorder ${ }^{1}$. The lifetime prevalence of GAD is around $5 \%$ and is more common in women than in men $^{2}$. The disorder is generally characterized by chronic features, with periods of exacerbation and recovery. For this reason, patients may need to use long-term medication ${ }^{3}$. In addition, GAD may have negative effects on the quality of life ${ }^{4,5}$.

Sexual dysfunctions (SD) are defined as disorders in desire, arousal and orgasm phases and painful sexual disorders in DSM-5 (American Psychiatric Association 2013). Symptoms related to SD are not often questioned on psychiatric examination. Although the frequency of psychiatric disorders associated with GAD has been assessed in many studies, the majority of large-scale studies have not been questioned $\mathrm{SD}^{2,6,7}$. SD frequency varies among societies. In a study conducted in Turkey, $48.3 \%$ of women had sexual dysfunction; it was reported that $48.3 \%$ of the participants of the study had deterioration in desire level, $35.9 \%$ in arousal level, $40.9 \%$ in lubrication level, $42.7 \%$ in orgasm level and $45.0 \%$ in satisfactory levels.

Sexual functions can affect many diseases. It has been reported that anxiety disorders increase the symptoms of $\mathrm{SD}^{9-11}$. Stress and anxiety cognitive processes can affect different endocrine and neurotransmitter systems and may cause negative effects on sexual function ${ }^{12}$. Anxiety has a repressive effect on sexual arousal and inhibits other stages of sexual functioning from occurring in a healthy way ${ }^{13}$. Medication used in the treatment of GAD also causes SD ${ }^{3}$. SD affects people's quality of life, interpersonal relations and self-esteem negatively ${ }^{14}$ and SD are one of the important factors affecting the general health status and quality of life of women.

Body image is a multidimensional concept involving the image, attitude, thoughts, feelings, and behaviors of one's body ${ }^{15,16}$. Body image has a decisive influence on one's self-esteem, eating behavior, anxiety levels, sexual behavior, functioning, social relations and emotional state. Body image is related to mental health ${ }^{17}$. Deterioration in mental health can cause someone not to like their own body ${ }^{18}$. As far as we know, no study has evaluated the relationship between SD, body image, and quality of life in GAD patients. In this study, it was aimed to compare patients with GAD with healthy controls in terms of SD, body image/perception and quality of life, and to investigate whether there is a relationship between these parameters in patients.

\section{Methods}

Forty seven female patients who applied to the Practice and Research Hospital Psychiatry Outpatient Clinic, were diagnosed as GAD by 2 different specialists (ÖK, YH) according to the DSM-5 diagnostic criteria $^{1}$ included to this study. 6 patients who were not fully filled in the scales were excluded from the study. At the end of the study, 41 female patients and 40 healthy female volunteers evaluated in statistical analysis. All participants were married. Patients whose age were ranging between 18 to 50 , who had regular sexual life included in the study. Patients with chronic illness, comorbid depression or other psychiatric illnesses, endocrine disorder (thyroid dysfunctions, diabetes, hypogonadism), local genital problems (vaginitis, pelvic infections), cardiovascular disease, renal and hepatic disease, neurological disorder, drug use that could impair sexual function or oral contraceptive, pregnant and lactation, physical disease or undergone surgery that could impair the physical appearance, alcohol or substance use disorder were not included in the study. This study was approved by the Ethics Committee of Yozgat Bozok University (2017-KAEK-189_2017.08.24_11), and a written consent form was obtained from all of the individuals prior to the study.

\section{Instruments and materials}

\section{Sociodemographic Information Form}

This form was prepared by the physicians who conducted the study in order to question the sociodemographic characteristics of the people taken into the study and their knowledge about the disease. Information about the age, marital status, education level, monthly income, working status of the people took place in the form. 


\section{Arizona Sexual Experiences Scale (ASEX)}

This is a Likert type scale consisting of 5 questions developed by McGahuey et al. ${ }^{19}$ Turkish validity and reliability of the scale were assessed by Soykan (2004) in patients who received dialysis treatment due to end-stage renal failure ${ }^{20}$. There are two forms of ASEX as for women and men. Sexual desire, arousal, penile erection/vaginal lubrication, orgasm and satisfaction of the orgasm are evaluated. Each question is scored between 1 and 6 and the total score is between 5-30. High scores indicate that the severity of the SD is high. A total score of 17 or above or 5 or more points from any question is considered as the SD.

\section{Short Form-36 (SF-36)}

This form, which is often used to measure the quality of life, was developed in $1992^{21}$. Scale was defined as physical function (10 items), social function (2 items), role limitations due to physical problems (4 items), role limitations due to emotional problems (3 items), mental health (5 items), energy/vitality (4 items), pain ( 2 items) and general health perceptions ( 5 items); total of 36 items. Scores from 0 to 100 are used in the scale evaluating the last 4 weeks and high scores indicate good health. Turkish validity and reliability study was conducted by Koçyiğit et al. ${ }^{22}$.

\section{Body Cathexis Scale (BCS)}

BCS was developed by Secord and Jourand ${ }^{23}$ and Turkish validity and reliability were made by Hovardaoğlu ${ }^{24}$. The scale consists of 40 items and aims to measure the levels of satisfaction of various parts of the body and body functions. There are 5 different responses for each item in the scales from 1 to 5 in the form of 'I do not like at all', 'I do not like,' 'I am indecisive,', 'I like it' and 'I like it very much', and the total score of the scale varies between 40-200. The high score indicates the level of satisfaction of the individual's body. The cutoff score of the scale was 135, and scores below that were defined as the low-level group.

\section{Beck Anxiety Inventory}

This is a Likert type scale, consisting of twenty-one questions, and it is the scale of self-assessment used to determine the severity of anxiety symptoms experienced by an individual. Each question has 4 options and is rated with a score between 0 and 3 . The high score on the scale indicates the severity of the anxiety of the person ${ }^{25}$. The validity and reliability of our country were made by Ulusoy et al. ${ }^{26}$.

\section{Statistical analysis}

NCSS (Number Cruncher Statistical System) 2007 (Kaysville, Utah, USA) program was used for statistical analysis. When the study data were evaluated, descriptive statistical methods (mean, standard deviation, median, 1 . quartile, 3 . quartile, minimum, maximum), as well as normal distributions of quantitative data, were tested with the Shapiro-Wilk test and graphical examinations. Independent groups t-test was used for the comparison of the two groups of normal distribution quantitative variables, Mann Whitney U test was used for the comparison between the two groups of quantitative variables without normal distribution. Pearson correlation analysis and Spearman correlation analysis were used to evaluating the relationships between quantitative variables. Statistical significance was accepted as $\mathrm{p}<0.05$.

\section{Findings}

The study was conducted with a total of 81 patients who applied to the Practice and Research Hospital Psychiatry Outpatient Clinic between October 2017 and January 2018. The ages of the cases ranged from
19 to 47 years with an average of $33,05 \pm 6,81$ years. The duration of education of the cases ranged from 5 to 16 years with an average of $9.33 \pm 3.88$ years (Table 1 ). High scores for SD were found in 18 $(44 \%)$ of GAD patients and in $7(17,5 \%)$ of the control group.

There was no statistically significant difference between the study and control groups in terms of age and duration of education $(p>0.05)$. In the study group, it was determined that the score for SD desire, arousal and orgasm subscale and scale total scores were statistically significantly higher than the control group scores $(\mathrm{p}=$ $0.007 ; \mathrm{p}=0.049 ; \mathrm{p}=0.002 ; \mathrm{p}=0.005$ respectively) (Table 2 ). There was no statistically significant difference between groups in terms of SD lubrication subscale scores $(\mathrm{p}>0.05)$ (Table 2). The BCS scores of the patient group were found to be statistically significantly lower than the control group scores $(\mathrm{p}<0.001)$. The Beck anxiety scale scores of the study group were found to be statistically significantly higher than the control group scores $(\mathrm{p}<0.001)$ (Table 2).

Table 1. Distribution of descriptive properties (all participants)

\begin{tabular}{|l|c|c|}
\hline & Min-Max & Mean \pm SD \\
\hline Age (years) & $19-47$ & $33.05 \pm 6.81$ \\
\hline Duration of education (years) & $5-16$ & $9.33 \pm 3.88$ \\
\hline Sexual dysfunction & & \\
\hline Desire & $1-6$ & $3.07 \pm 1.19$ \\
\hline Arousal & $1-6$ & $3.05 \pm 1.09$ \\
\hline Lubrication & $1-6$ & $2.78 \pm 0.99$ \\
\hline Orgasm & $1-6$ & $3.26 \pm 0.98$ \\
\hline Satisfaction & $1-6$ & $3.00 \pm 0.97$ \\
\hline Sexual dysfunction total & $7-26$ & $15.16 \pm 4.21$ \\
\hline Body Cathexis Scale & $97-198$ & $147.77 \pm 21.84$ \\
\hline BECK Anxiety & $4-59$ & $22.21 \pm 14.01$ \\
\hline SF-36 & & \\
\hline Physical Function & $10-30$ & $22.33 \pm 5.19$ \\
\hline Physical Role Difficulty & $4-8$ & $6.02 \pm 1.41$ \\
\hline Pain & $2-11$ & $9.10 \pm 1.84$ \\
\hline General Health & $13-25$ & $20.80 \pm 3.27$ \\
\hline Vitality & $0-24$ & $18.85 \pm 4.47$ \\
\hline Social Function & $2-10$ & $6.49 \pm 2.04$ \\
\hline Emotional Role Difficulty & $3-6$ & $4.53 \pm 1.01$ \\
\hline Mental Health & $5-30$ & $17.77 \pm 5.30$ \\
\hline
\end{tabular}

SF-36: Short Form-36.

Table 2. Inter-group evaluations

\begin{tabular}{|c|c|c|c|}
\hline & Control $(n=40)$ & Study $(n=41)$ & $p$ \\
\hline $\begin{array}{l}\text { Occupation } \\
\text { Work } \\
\text { Unemployed }\end{array}$ & $\begin{array}{l}26(\% 65) \\
14(\% 35)\end{array}$ & $\begin{array}{l}23(\% 56) \\
18(\% 44)\end{array}$ & \\
\hline & $\begin{array}{l}\text { Median ( } 25 \% \\
\text { per- } 75 \% \text { per) }\end{array}$ & $\begin{array}{l}\text { Median }(25 \% \\
\text { per- } 75 \% \text { per })\end{array}$ & \\
\hline Age (years); mean \pm sd & $33.23 \pm 6.70$ & $32.88 \pm 6.98$ & $0.820^{\mathrm{a}}$ \\
\hline 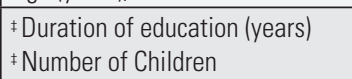 & $\begin{array}{c}10.5(5,12) \\
2(2,3)\end{array}$ & $\begin{array}{l}8(5,12) \\
2(1,3)\end{array}$ & $\begin{array}{l}0.369^{b} \\
0.932^{b}\end{array}$ \\
\hline ¥Sexual dysfunction - Desire & $3(2,3)$ & $3(3,4)$ & $0.007 b^{* * *}$ \\
\hline ₹Sexual dysfunction - Arousal & $3(2,3)$ & $3(2.5,4)$ & $0.049 b_{i}^{*}$ \\
\hline ‡ Sexual dysfunction - Lubrication & $3(2,3)$ & $3(2,4)$ & $0.315^{b}$ \\
\hline ‡Sexual dysfunction - Orgasm & $3(2,3)$ & $4(3,4)$ & $0.002 b^{* * *}$ \\
\hline ‡ Sexual dysfunction - Satisfaction & $3(2,3)$ & $3(3,4)$ & $0.054 b$ \\
\hline Sexual dysfunction - Total & $13.85 \pm 3.58$ & $16.44 \pm 4.41$ & $0.005^{a},{ }^{* *}$ \\
\hline Body Cathexis Scale; Mean \pm sd & $158.65 \pm 17.64$ & $137.15 \pm 20.40$ & $<0.001_{1}{ }^{* *}$ \\
\hline Beck Anxiety Scale & $12(8.25,13)$ & $33(22.5,41.5)$ & $<0.001 b^{* *}$ \\
\hline
\end{tabular}

a Independent groups t-test; ${ }^{\circ}$ Mann Whitney $\mathrm{U}$ test; ` Relevant data is presented in median (1 ${ }^{\text {st }}$ quartile, $3^{\text {rd }}$ quartile); ${ }^{*} p<0.05 ;{ }^{* *} p<0.01$. 
There was a statistically significant correlation in a negative way between the BCS score of the cases and SD desire, arousal, lubrication, orgasm subscale scores and scale total scores ( $\mathrm{r}:-0.305$, p:0.006; r:-0.259, p:0.019; r:-0.285, p:0.010; r:-0.348, p:0.001; r:-0.305, p:0.002, respectively). No statistically significant relationship was found between the scores of the body cathexis scale and the sexual dysfunction - satisfaction subscale of the cases $(p>0.05)$ (Table 3$)$. There was a statistically significant correlation between the duration of education and sexual dysfunction-satisfaction subscale scores at a negative level (r:-0.225, p:0.043).

In the study group, SF-36 physical function, general health and mental health subscale scores were found to be statistically significantly lower than control group scores $(p=0.001 ; p=0.014$; $\mathrm{p}=0.001$, respectively). In the study group, SF-36 energy subscale scores were not statistically significantly lower but they were almost significantly lower than the scores of the control group ( $\mathrm{p}=0.056$; $\mathrm{p}>0.05$ ) (Table 4).

Table 3. Assessing the relationship levels between body image and sexual dysfunction

\begin{tabular}{|l|c|c|}
\hline \multirow{2}{*}{} & \multicolumn{2}{|c|}{ Body Cathexis Scale } \\
\cline { 2 - 3 } & $\mathrm{r}$ & $\mathrm{p}$ \\
\hline Sexual Dysfunction - Desire & -0.305 & $0.006^{\mathrm{c}, * *}$ \\
\hline Sexual Dysfunction - Arousal & -0.259 & $0.019^{\mathrm{c},}{ }^{*}$ \\
\hline Sexual Dysfunction - Lubrication & -0.285 & $0.01 \mathrm{c}^{*}{ }^{*}$ \\
\hline Sexual Dysfunction - Orgasm & -0.348 & $0.001 \mathrm{c}^{*}{ }^{*}$ \\
\hline Sexual Dysfunction - Satisfaction & -0.208 & $0.063^{\mathrm{c}}$ \\
\hline Sexual Dysfunction - Total & -0.338 & $0.002^{\mathrm{d}, * *}$ \\
\hline
\end{tabular}

c Spearman correlation analysis; d Pearson correlation analysis. ${ }^{*} p<0.05 ;{ }^{* *} p<0.01$.

Table 4. Inter-group evaluations

\begin{tabular}{|c|c|c|c|}
\hline & Control $(n=40)$ & Study $(n=41)$ & \multirow[t]{2}{*}{$p$} \\
\hline & $\begin{array}{l}\text { Median (25\% } \\
\text { per- } 75 \% \text { per) }\end{array}$ & $\begin{array}{l}\text { Median }(25 \% \\
\text { per- } 75 \% \text { per) }\end{array}$ & \\
\hline SF-36 - Physical Function & $24(22,27.5)$ & $20(15.5,24)$ & $0.001 b^{* *}$ \\
\hline $\begin{array}{l}\text { SF-36 - Physical Role } \\
\text { Difficulty去 }\end{array}$ & $6(5,7)$ & $6(5,7)$ & $0.761 \mathrm{~b}$ \\
\hline SF-36 - Pain & $9.1(9,10.4)$ & $9(8,10.40)$ & $0.467 \mathrm{~b}$ \\
\hline SF-36 - General Health ${ }^{\ddagger}$ & $22(20,24.40)$ & $20(18,22)$ & $0.014^{\mathrm{b}},{ }^{*}$ \\
\hline SF-36 - Energy (Vitality) $)^{\ddagger}$ & $20(18,22)$ & $20(16,20)$ & $0.056^{\mathrm{b}}$ \\
\hline SF-36 - Social Function & $7(5,8)$ & $6(5,8)$ & $0.398^{b}$ \\
\hline $\begin{array}{l}\text { SF-36 - Emotional Role } \\
\text { Difficulty }\end{array}$ & $5(4,6)$ & $4(4,5)$ & $0.093^{b}$ \\
\hline SF-36 - Mental Health & $20(16.25,25)$ & $15(12,17)$ & $<0.001 a^{a *}$ \\
\hline
\end{tabular}

a Independent groups t-test; ${ }^{\mathrm{b}}$ Mann Whitney $\mathrm{U}$ test. ₹ Relevant data is presented in median (1 st quartile, 3rd quartile). ${ }^{*} p<0.05 ;{ }^{* *} p<0.01$.

\section{Discussion}

In this study, sexual dysfunction, quality of life and body image of the female, drug-free GAD patients who applied for an outpatient therapy to a psychiatric clinic of a university hospital and healthy individuals were compared. In the study, there was a significant deterioration in the sexual desire, arousal, orgasm levels in the GAD group compared to the control group. As the duration of education increased in all cases, the satisfaction related disorders decreased.

A number of psychological factors can be mentioned in the etiology of $\mathrm{SD}^{13}$. Anxiety disorders can be effective in the emergence of $\mathrm{SDs}^{27}$. In an epidemiological study, moderate and high anxiety values in women were reported to be associated with the risk of developing sexual problems by inhibition of stimulation, orgasm, and satisfaction ${ }^{28}$. In the study of Dèttore et al. ${ }^{10}$, panic disorder (PD), GAD, and a control group were compared; and it was found that there was no difference in sexual function between PD and GAD. When compared with the group containing PD and GAD to the control group; significant deterioration was found according to arousal, orgasm, satisfaction and general sexual functioning in comparison with the control group. In women with PD or GAD, a negative correlation was found between state and trait anxiety and subjective arousal. Anxiety can cause negative effects on sexual function with different mechanisms. It can be suggested that an increase in anxiety leads to cognitive interference, followed by decreased attention to sexual stimuli and misinterpretations of these stimuli ${ }^{11}$. Anxious people perceive physiological sexual stimulation as anxiety-provoking and tend to concentrate their attention on threatening. As a result, they are reported to have more anxiety and less subjective reactions to sexual arousal.

Anxiety at the physiological level is highly stimulating rather than inhibiting sexual functions. This is the result of stimulation of the sympathetic nervous system ${ }^{29}$ For this reason, anxiety in healthy individuals does not adversely affect sexual stimulation ${ }^{30}$.

The frequency of SD accompanying psychiatric diseases varies. In the study of Kendurkar et al. ${ }^{31}$, the incidence of sexual dysfunction was $30 \%$ in healthy controls and $64 \%$ in GAD. In the same study, there was a significant increase in desire, arousal, orgasm and total points in the women with GAD as compared to the control group, namely sexual dysfunction. The deterioration in the desire, arousal, orgasm and total scores of sexuality, which was also determined in our study, was matching with the results of the study of Kendurkar et al. ${ }^{31}$. In our study, $44 \%$ of the GAD patients and $17.5 \%$ of the control group had high scores for SD.

It has been reported that a low level of education increases the risk of having sexual dysfunction in the studies ${ }^{32,33}$. It has been argued that the low level of education may prevent the information given to the individuals from being implemented in a satisfactory manner and may cause sexual problems to increase ${ }^{33}$. In our study, as the duration of education increased in all cases, satisfactory related disorders were reduced. This result shows that education has a positive influence on sexuality.

In GAD cases, the body cathexis scale scores were found to be lower than the control group scores. This shows that GAD patients are more dissatisfied with their bodies. There is a significant relationship between body sensation and mental health ${ }^{17}$. Deterioration in mental health also results in less admiring of one's body ${ }^{18}$. The deterioration of the body image of GAD patients can also be explained by this situation. As dissatisfaction with the body sensation increased in our study group, the sexual dysfunction increased in the areas of desire, arousal, lubrication, orgasm. Deterioration in body image leads to avoidance of sexual activities in both genders ${ }^{34}$. In addition, it has been reported that women who received a diagnosis of SD found themselves less attractive than non-diagnosed women ${ }^{35}$. The findings of the SD in GAD patients may be due to impairment both from anxiety and body image. As a result, it can be said that anxiety, sexual functions, and body image are mutually influential factors.

SF-36 physical function, general health, mental health scores were lower in the GAD group than the control group. Anxiety symptoms and the chronic nature of the disease in GAD may lead to deteriorations in the quality of life. Anxiety disorders such as panic disorder ${ }^{36}$ and $\mathrm{GAD}^{4,37}$ have been reported to impair quality of life. The results of our study are consistent with literature data.

In conclusion, this study found that there was a significant deterioration in sexual function of GAD patients and that this disorder was almost in all areas of sexuality. GAD appears to be adversely affecting the quality of life due to its chronic nature. In addition, it was decided that the increase in body dissatisfaction in these patients affects sexual functions negatively. From these results, it is important to not only improve the symptoms of the illness in the follow-up and treatment of the patients but also to question the deterioration in these areas and to arrange the treatment plan accordingly.

There are limitations in the study such as the fact that only married and female gender has been evaluated, the number of cases is low, a cross-sectional study has been carried out, a detailed 
psychiatric evaluation of sexual dysfunction has not been made and sexual orientation, sexual activity and sexual partnership data has not been asked at sexual history. Another limitation is that the scale used in the study is the self-report assessment. Patient and control group were selected from participants with similar sociodemographic factors and physical disorders. Nevertheless sexual functioning is affected by many factors, so it is not possible to provide similarity of groups. Follow-up studies in which both genders are evaluated together and the effect of treatment on the larger number of cases is assessed with comprehensive scales will contribute to the acquisition of consistent scientific data in this area.

\section{References}

1. Association AP. Diagnostic and statistical manual of mental disorders (DSM-5 ${ }^{\circ}$ ): American Psychiatric Pub; 2013.

2. Wittchen HU. Generalized anxiety disorder: prevalence, burden, and cost to society. Depress Anxiety. 2002;16(4):162-71.

3. Saatçioğlu Ö. Treatment of generalized anxiety disorder and new approaches. KLIN PSIKOFARMAKOL B Journal. 2001;11(1):60-77.

4. Bourland S, Stanley MA, Snyder A, Novy D, Beck J, Averill P, et al. Quality of life in older adults with generalized anxiety disorder. Aging Ment Health. 2000;4(4):315-23.

5. Geale K, Henriksson M, Schmitt-Egenolf M. The Relationship Between Disease Severity and Quality of Life In Patients With Moderate to Severe Psoriasis. Value Health. 2015;18(7):A675.

6. Ozcan M, Uguz F, Cilli AS. The prevalence of generalized anxiety disorder and comorbidity among psychiatric outpatients. Turk Psikiyatri Derg. 2006;17(4):276.

7. Wittchen HU, Hoyer J. Generalized anxiety disorder: nature and course. J Clin Psychiatry. 2001;62 Suppl 11:15-9; discussion 20-1. 8. Oksuz E, Malhan S. Prevalence and risk factors for female sexual dysfunction in Turkish women. J Urol. 2006;175(2):654-8.

9. Karaaslan Ö. Sosyal anksiyete bozukluğu hastalarında beden algısı ve cinsel işlev bozukluklarının değerlendirilmesi. Bozok Tip Derg. 2017;7(2):45-50.

10. Dèttore D, Pucciarelli M, Santarnecchi E. Anxiety and female sexual functioning: An empirical study. J Sex Marital Ther. 2013;39(3):216-40.

11. van den Hout $M$, Barlow $D$. Attention, arousal and expectancies in anxiety and sexual disorders. J Affect Disord. 2000;61(3):241-56.

12. Graziottin A. Libido: the biologic scenario. Maturitas. 2000;34:S9-S16.

13. Çeri Ö, Yilmaz A, Soykan A. Cinsel İşlev Bozukluklari. Turkiye Klinikleri J Psychiatry-Special Topics. 2008;1(2):71-8.

14. Croft H, Settle Jr E, Houser T, Batey SR, Donahue RM, Ascher JA. A placebo-controlled comparison of the antidepressant efficacy and effects on sexual functioning of sustained-release bupropion and sertraline. Clin Ther. 1999;21(4):643-58.

15. Cash TF. Body image: Past, present, and future. Elsevier; 2004.

16. Cohen A. Body image in the person with a stoma. J Enterostomal Ther. 1991;18(2):68-71.

17. Dökmen Y. Menopoz, beden imgesi ve ruh sağliği. Türk Psikoloji Yazilari. 2009;12(24):41-55.
18. McCabe MP, Ricciardelli LA, Sitaram G, Mikhail K. Accuracy of body size estimation: Role of biopsychosocial variables. Body image. 2006;3(2):163-71.

19. McGahuey CA, Gelenberg AJ, Laukes CA, Moreno FA, Delgado PL, McKnight KM, et al. The Arizona Sexual Experience Scale (ASEX): reliability and validity. J Sex Marital Ther. 2000;26(1):25-40.

20. Soykan A. The reliability and validity of Arizona sexual experiences scale in Turkish ESRD patients undergoing hemodialysis. Int J Impot Res. 2004;16(6):531-4. 21. Ware JE Jr., Sherbourne CD. The MOS 36-item short-form health survey (SF-36). I. Conceptual framework and item selection. Medical Care. 1992;30(6):473-83.

22. Koçyigit H. Kisa Form-36 (KF-36)'nm Turkce versiyonunun guvenilirligi ve gecerliligi. Ilac ve Tedavi Dergisi. 1999;12:102-6.

23. Secord PF, Jourard SM. The appraisal of body-cathexis: Body-cathexis and the self. J Consult Psychol. 1953;17(5):343-7.24.Hovardaoğlu S. Vücut algısı ölçeğinin güvenirlik ve geçerlik çalışması. İçinde: Özdemir YD (1990) Şizofrenik ve majör depresif hastaların beden imgelerinden doyum düzeyleri Yayınlanmamıs Yüksek Lisans Tezi, Ankara, Sosyal Bilimler Enstitüsü; 1990.

25. Beck AT, Epstein N, Brown G, Steer RA. An inventory for measuring clinical anxiety: psychometric properties. J Consult Clin Psychol. 1988;56(6):893-7.

26. Ulusoy M, Sahin NH, Erkmen H. Turkish version of the Beck Anxiety Inventory: psychometric properties. J Cogn Psychother. 1998;12(2):163.

27. İncesu C. Cinsel işlevler ve cinsel işlev bozuklukları. Klinik Psikiyatri Dergisi. 2004;7(Suppl 3):3-13.

28. Dunn KM, Croft PR, Hackett GI. Association of sexual problems with social, psychological, and physical problems in men and women: a cross sectional population survey. J Epidemiol Community Health. 1999;53(3):144-8.

29. Meston CM, Gorzalka BB. The effects of sympathetic activation on physiological and subjective sexual arousal in women. Behav Res Ther. 1995;33(6):651-64.

30. Van Minnen A, Kampman M. The interaction between anxiety and sexual functioning: A controlled study of sexual functioning in women with anxiety disorders. Sexual Relation Ther. 2000;15(1):47-57.

31. Kendurkar A, Kaur B. Major depressive disorder, obsessive-compulsive disorder, and generalized anxiety disorder: do the sexual dysfunctions differ? Primary care companion to the J Clin Psychiatr 2008;10(4):299.

32. Laumann EO, Paik A, Rosen RC. Sexual dysfunction in the United States: prevalence and predictors. JAMA. 1999;281(6):537-44.

33. Bahar A, Savas AH, Yildizgördü E, Barlioglu H. Hemodiyaliz hastalarinda anksiyete, depresyon ve cinsel yasam1/Anxiety, depression and sexual life of hemodialysis patients. Anadolu Psikiyatri Derg. 2007;8(4):287.

34. Faith MS, Schare ML. The role of body image in sexually avoidant behavior. Arch Sex Behav. 1993;22(4):345-56

35. Metz ME, Epstein N. Assessing the role of relationship conflict in sexual dysfunction. J Sex Marital Ther. 2002;28(2):139-64.

36. Carrera M, Herrán A, Ayuso-Mateos JL, Sierra-Biddle D, Ramírez ML, Ayestarán A, et al. Quality of life in early phases of panic disorder: predictive factors. J Affect Disord. 2006;94(1):127-34

37. Henning ER, Turk CL, Mennin DS, Fresco DM, Heimberg RG. Impairment and quality of life in individuals with generalized anxiety disorder. Depress Anxiety. 2007;24(5):342-9. 